\title{
Regulatory T Cells and Acute Lung Injury: Cytokines, Uncontrolled Inflammation, and Therapeutic Implications
}

\author{
Shihui Lin', Hua $W^{2}{ }^{2}$, Chuanjiang Wang ${ }^{1}$, Zhibo Xiao ${ }^{3}$ and Fang $X u^{1 *}$ \\ 'Department of Emergency and Critical Care Medicine, The First Affiliated Hospital of Chongqing Medical University, \\ Chongqing, China, ${ }^{2}$ Center for Cognitive and Neurobiological Imaging, Stanford University, Stanford, CA, United States, \\ ${ }^{3}$ Department of Radiology, The First Affiliated Hospital of Chongqing Medical University, Chongqing, China
}

\section{OPEN ACCESS}

Edited by:

Rudolf Lucas,

Augusta University,

United States

Reviewed by:

Nona Janikashvili,

Tbilisi State Medical

University, Georgia

Gabriele Multhoff,

Technische Universität

München, Germany

*Correspondence:

Fang $X u$

xufang828@126.com,

fangxu@stanford.edu

Specialty section: This article was submitted to Inflammation,

a section of the journal

Frontiers in Immunology

Received: 27 February 2018 Accepted: 21 June 2018

Published: 09 July 2018

Citation:

Lin S, Wu H, Wang C, Xiao Z and XU F (2018) Regulatory T Cells and

Acute Lung Injury: Cytokines,

Uncontrolled Inflammation, and

Therapeutic Implications.

Front. Immunol. 9:1545.

doi: 10.3389/fimmu.2018.01545
Acute respiratory distress syndrome/acute lung injury (ALI) was described in 1967. The uncontrolled inflammation is a central issue of the syndrome. The regulatory $T$ cells (Tregs), formerly known as suppressor $\mathrm{T}$ cells, are a subpopulation of $\mathrm{T}$ cells. Tregs indirectly limits immune inflammation-inflicted tissue damage by employing multiple mechanisms and creating the appropriate immune environment for successful tissue repair. And it plays a central role in the resolution of ALI. Accordingly, for this review, we will focus on Treg populations which are critical for inflammatory immunity of ALI, and the effect of interaction between Treg subsets and cytokines on ALI. And then explore the possibility of cytokines as beneficial factors in inflammation resolution of ALI.

Keywords: regulatory T cells, acute lung injury, acute respiratory distress syndrome, uncontrolled inflammation, cytokines

\section{INTRODUCTION}

After the initial description of acute respiratory distress syndrome (ARDS) (1967), great progress has been made in the study of the pathophysiology and pathogenesis of acute lung injury (ALI) (1-5), and much has been learned about the pathogenesis of lung injury in ARDS. Uncontrolled inflammation is a central issue in ALI, and understanding how this is regulated is important for developing new treatment strategies for limiting excessive inflammation.

Throughout human life, $\mathrm{T}$ cell system adjusts to the transfer of resources and needs, resulting in a fundamentally reorganized immune system in each individual (6). In ALI, central to these issues is the large variety of $\mathrm{T}$ cells implicated in the pathobiology, pathophysiology, and integration of innate and adaptive immunity leading to uncontrolled pulmonary inflammation. Regulatory $\mathrm{T}$ cells (Tregs) are a special type of $\mathrm{T}$ cell. It could restrict inflammation-induced tissue damage via multiple mechanisms indirectly, such as their anti-inflammatory and antiapoptotic abilities (7), to create an appropriate immune microenvironment for the repairing and regeneration of tissue (8). And it is possible that a kernel mechanism of inhibition may be commonly used by Tregs at any location (e.g., spleen, blood, and lung) or in any inflammatory environment or phase $(9,10)$.

In order to understand the intricate and dynamic interactions between functionally activated Tregs and the pathophysiology of ALI, it is necessary to analyze the function of specialized T cells in uncontrolled inflammation, the ultimate goal being to identify new therapeutic approaches. In this review, we confine our discussion to Treg populations that play a critical role in the development of uncontrolled inflammation in ALI. 


\section{UNCONTROLLED INFLAMMATION: A CORE ISSUE IN ALI}

At present, it is generally accepted that ALI is characterized by rapid alveolar injury, inflammation, cytokine induction, and neutrophil accumulation, with an emphasis on the mechanisms of injury to the lung endothelium and the alveolar epithelium. ARDS represents a stereotypic response to various etiologies. It progresses through different phases, starting with alveolar capillary damage, progressing, to lung resolution, and culminating in a fibroproliferative phase. A hallmark of the damage seen in ARDS is that it is not uniform. A major challenge faced in a clustering approach is the heterogeneity of ALI, not only between patients but also in the same patient from a different cause or at different stages of the disease. All of these complex factors make it extremely difficult to improve the understanding about pathogenesis and treatment in ARDS.

The core mechanisms of ALI may involve trauma, tissue damage, infection, shock (except for cardiogenic shock), or conserved microbial or molecular patterns that trigger receptors on innate immune cells. As a result, series of pro-inflammatory and antiinflammatory cytokines (or chemokine) are produced.

Recent meta-analyses about a network clinical trials of ARDS, including the measurements of blood biomarkers and clinical indicators, indicate that approximately $35 \%$ of patients with ARDS have high inflammatory endocrine, which related to higher mortality (11). Cytokines are proteins with pro-inflammatory or anti-inflammatory effects. Its biological effects need to be completed by autocrine and paracrine manner. Several studies have also reported a number of cytokines-such as TNF- $\alpha$ (12, 13), IL-1 $\beta$ (14), IL-6 (15), IL-17 (16, 17), and IL-33 (18, 19) - were increased in acute stage of ARDS/ALI. Based on these findings, which point to the inflammatory complexity of this disease, ALI must be seen as a syndrome with many manifestations both systemic and pulmonary. By focusing on and exploring the uncontrolled inflammation of ARDS, we hope to come closer to defining its causes and development.

\section{Treg: T CELLS WITH ANTI- INFLAMMATORY FUNCTIONS}

Response to exogenous or endogenous insults, the host brings a range of changes characterized by transform in immune function and the produce of mediators called cytokines. A large number of studies have found that these immunoregulatory mechanisms are beneficial in that they prevent the worsening of injury and promote its repair (20-22). Data also show that inflammatory cytokines contribute to the development and progression of many immunologic and inflammatory diseases $(23,24)$, suggesting that therapeutic actions may be promoted by regulating these mediators. But the immune system-divided into innate and adaptive branches-comprises many different cell types that vary by both function and topographic location. $\mathrm{T}$ and $\mathrm{B}$ lymphocytes constitute the major cellular components of the adaptive immune response (25). More than any other cellular system, cell-mediated immune responses are largely controlled by T cells. Environmental factors have frequently been associated with providing the trigger that enables or enhances the development of T-cell immunity in sensitive individuals (26). Many additional aspects of T-cell function can be altered by the local cytokine or chemokine environment. Therefore, by exploring the pathogenesis of uncontrolled inflammation in ALI, we may be able to clarify the functioning of T-cell immunology.

Several Th subsets within the T-cell immune system are now well defined, including Th1, Th2, Tregs, follicular helper T cells, Th17, Th22, and Th25 (26-28). A central question in T-cell immunology is how this group of CD4 T cells can coordinate such diverse immunologic processes involving so many different cell types. A central question in T-cell immunology is how this group of CD4 T cells can coordinate such diverse immunologic processes involving so many different cell types. Tregs are a subtype of $\mathrm{CD}^{+} \mathrm{T}$ cells known to be significant for immune homeostasis and maintaining self-tolerance; they were termed suppressor cells originally (29). On the basis of the relative differentiation state and the tissues where Tregs are generated primarily, they can be separated into several subsets, including two major subgroups. One subgroup is a distinct lineage (tTregs) from thymus, the other originate from the peripheral conversion of naive $\mathrm{CD} 4{ }^{+} \mathrm{CD} 25^{-}$(Tconvs) into Tregs (pTregs) induced by FoxP3 (30). The interaction of Naive or resting Tregs are lower than the threshold with full activation, but the changes of effector Tregs in surface markers and enhanced suppression. Memory Tregs reacted against antigen and had survivability for quite a time indeed in the absence of antigen apparently. In the suspicion, memory Tregs alleviate tissue damage during the deepen reactions of pro-inflammatory memory cells $(31,32)$. In the research about ALI, it is an unknown area. However, from the aspects of lung development, pulmonary fibrosis, lung injury and repair, etc., which controlled by inflammation, the characteristics of Treg subtypes should play an important role in ALI and need to be confirmed.

Human Tregs were first characterized as $\mathrm{CD} 4^{+} \mathrm{CD} 25^{+} \mathrm{T}$ cells in $2001(33,34)$; subsequent studies have confirmed transcription factor FoxP3 as a specific regulatory marker of human Tregs (35), which are believed to be important for maintaining immune homeostasis. Numerous publications have reported that the reduced generation or deficient function of Tregs is associated with greater disease severity and activity, as noted in patients with various inflammatory diseases (36). Current studies have also shown that Tregs can limit effector T-cell function $(37,38)$, which is known to infection control or mediating inflammatory injury (39). The most critical population of Tregs, which expresses Foxp3, can limit the activation, proliferation, and effector roles in series of immune cells $(40-42)$. CD $4^{+} \mathrm{CD} 25^{+}$Foxp $3^{+}$ Tregs are a representative cell type. And it is one of the powerful immunomodulators for adaptive immune system, functionally differentiated to be able to control Th1- or Th2-type immune responses by regulating the expression of Th1- or Th2-related transcription factors specifically as well as the activation of monocytes/macrophages $(43,44)$. However, although each subset of Tregs was functionally suppressive, they displayed unique inflammatory response patterns about inflammatory factor (proor anti-) formation, expressed lineage-specifying transcription 
factors differentially, after comprehensive functional analysis about various Tregs subsets (27). Studies showed that there is a difference between $\mathrm{CD} 4{ }^{+} \mathrm{CD} 45 \mathrm{RO}^{+} \mathrm{CD} 25^{\text {hi }} \mathrm{CD} 127^{\text {lo }}$ Tregs and $\mathrm{CD}^{+} \mathrm{CD} 45 \mathrm{RO}^{+} \mathrm{CD} 25^{-}$Th cells in chemokine (C-C motif) receptor 6 (CCR6), CXCR3, CCR4, and CCR10 from peripheral blood. It could not find the CCR4 $4^{-} / \mathrm{CCR} 4^{-} \mathrm{CCR} 10^{-}$phenotypic in the above type of Tregs. Due to their phenotypic similarity with different effector $\mathrm{T}$ cell subsets, we considered these populations as Th1-, Th2-, Th17-, and Th22-like Tregs. As described in Th cells, these acquisition of homing receptor phenotypes probably happens after the activation of periphery Tregs (27).

Although natural (n)Tregs are usually stable and long-lived, Tregs may demonstrate instability under pathogenic or inflammatory circumstances (45), and the stability and plasticity of Foxp3 has been under debate. Tregs instability is marked by the loss of Foxp3 expression and suppressive capacity as well as acquisition of features reminiscent of exFoxp3 cells (effector $\mathrm{T}$ cells by $\mathrm{CD} 25^{\text {lo }} \mathrm{Foxp} 3^{+} \mathrm{CD} 4{ }^{+} \mathrm{T}$ cells lose Foxp 3 expression) in response to environmental cues $(45,46)$. Studies showed that exFoxp3 Th17 cells, characterized by the expression of Sox4, chemokine (C-C motif) ligand 20, CCR6, IL-23 receptor, and receptor activator of NF- $\mathrm{KB}$ ligand, were more potent osteoclastogenic $\mathrm{T}$ cells than naïve $\mathrm{CD}^{+} \mathrm{T}$ cell-derived Th17 cells in autoimmune arthritis (RA) (46). On other hand, the balance between IL-2 and IL- 6 should regulate the development of Treg and Th17 cells from naive $\mathrm{CD} 4^{+} \mathrm{T}$ cells (47), and the fate of plastic Foxp $3^{+} \mathrm{T}$ cells may be determined by the cytokine balance too (48). Moreover, Th17 cells were shown to transdifferentiate into another Tregs subset, IL-10+ $\mathrm{T}$ regulatory type 1 cells during the resolving of inflammation (49). An additional source of Tregs includes Th17 cell transdifferentiation into ex-Th17 IL-17 ${ }^{\text {neg }}$ Foxp $3^{+}$cells (50). It can be seen that the instability of Tregs in an inflammatory state plays a vital function in the occurrence of diseases. In many autoimmune inflammatory conditions, Tregs plays an anti-inflammatory role, which when it fails, also leads to the development of inflammatory sickness. In several lung diseases, Tregs are in capacity of anti-inflammatory by the contact dependence inhibition or release of cytokines (IL-10, TGF- $\beta 1$, and INF- $\gamma$ ) mainly $(29,51-53)$. The expression of the required receptors making Tregs susceptible to these modulating cytokines is initiated only after activation and possibly also some lineage commitment. In addition and more importantly, the number and functional status of Tregs that could produce different cytokines (IL-10 and IFN- $\gamma$ ) or small-molecule proteins (perforin and granzyme) were not the same in different tissues or microenvironments $(51,54,55)$. In other words, Tregs can bring into play their functions through a variety of inhibitory mechanisms; however, exactly how Tregs employ these mechanisms in ALI remains unclear.

\section{Tregs IN ALI: METRONOME OF "INFLAMMATORY FACTOR STORM" REGULATION}

An infaust outcome of ARDS is related to the initial excessive pulmonary inflammation, which continues over time (56). Many modulators of inflammation were found to be increased in patients with high risk of ARDS who later died. And cytokines play a significant role in the development of lung region immunity. For distinct effector cytokines, Tregs should act as a "cytokine sink." And inflammation-specific Tregs work out an environment-specific inhibitory activity by the function. Studies have demonstrated a core role for Tregs in the alleviating or treating of ALI/ARDS in that they orchestrate a complex series of therapeutic events $(20,57)$. We now know that even in the pathophysiology of indirect ALI-which we used to described as a pro-inflammatory pathology mediated by cells of the innate immune system-cells of the adaptive immune response play a major role (58) (Figure 1).

\section{TNF- $\alpha$ AND IL-10}

The role of TNF- $\alpha$ as a major test indicator chosen for almost all clinical or basic research on the uncontrolled inflammation of ARDS is both important and obvious. Although there was a little difference in the increase of TNF- $\alpha$ in lipopolysaccharides (LPS) and oleic acid (OA)-induced ALI models, the overall increase was significant [except for the arterial or mixed venous blood samples of OA in pig models (59)]. Research has shown that cure with TNF- $\alpha$-specific antibody restored Tregs function in rheumatoid arthritis, which was related to decreasing the expression of protein phosphatase 1 and increasing the phosphorylation of Foxp3 in Tregs (60). Current research on ARDS has confirmed that transplantation of human umbilical cord mesenchymal stem cells improves ALI by increasing the alveolar Tregs and balancing pro- and anti-inflammatory factors (including TNF- $\alpha$ ) in ALI model (61).

IL-10 is an anti-inflammatory cytokine. Tregs can produce IL-10 to suppress hypernomic immune responses and thus to protect the host (62). This may have an important protective role in ALI, as by ameliorating the lung tissue injury by restraining production of TNF- $\alpha$ and neutrophil activity (63), IL-10 is produced during lung injury and significantly contributes to rapid early immunopathogenesis. During indirect ALI, the regulatory mechanisms of lung activated are mediated by the specific subgroup of $\mathrm{CD} 4^{+} \mathrm{CD} 25^{+} \mathrm{Foxp}^{+}$Tregs that are central to the domination of neutrophil recruitment by increasing the production of IL-10 (58). In transfusion-related ALI, CD $11 c^{+}$ dendritic cells and Tregs were the key effectors in regulating IL-10 (64). Interestingly, analyses in mice have shown that IL-10 production by Tregs was not required to control systemic autoimmunity, but it was necessary for keeping immunologic responses at the environmental/lung interface (51). Obviously, the IL-10 expression is regulated by Tregs in the progress of ALI, and sometimes the effect of IL-10 may inhibit the TNF- $\alpha$ production.

\section{TGF- $\beta$, IL-6, AND IL-2}

The development of Tregs requires TGF- $\beta$, while IL- 6 and IL- 2 are pivotal regulators obstructing the polarization of Tregs from naive $\mathrm{T}$ cells $(65,66)$. In the research using a mouse model of ALI, the presence of Tregs led to the increased local expression 


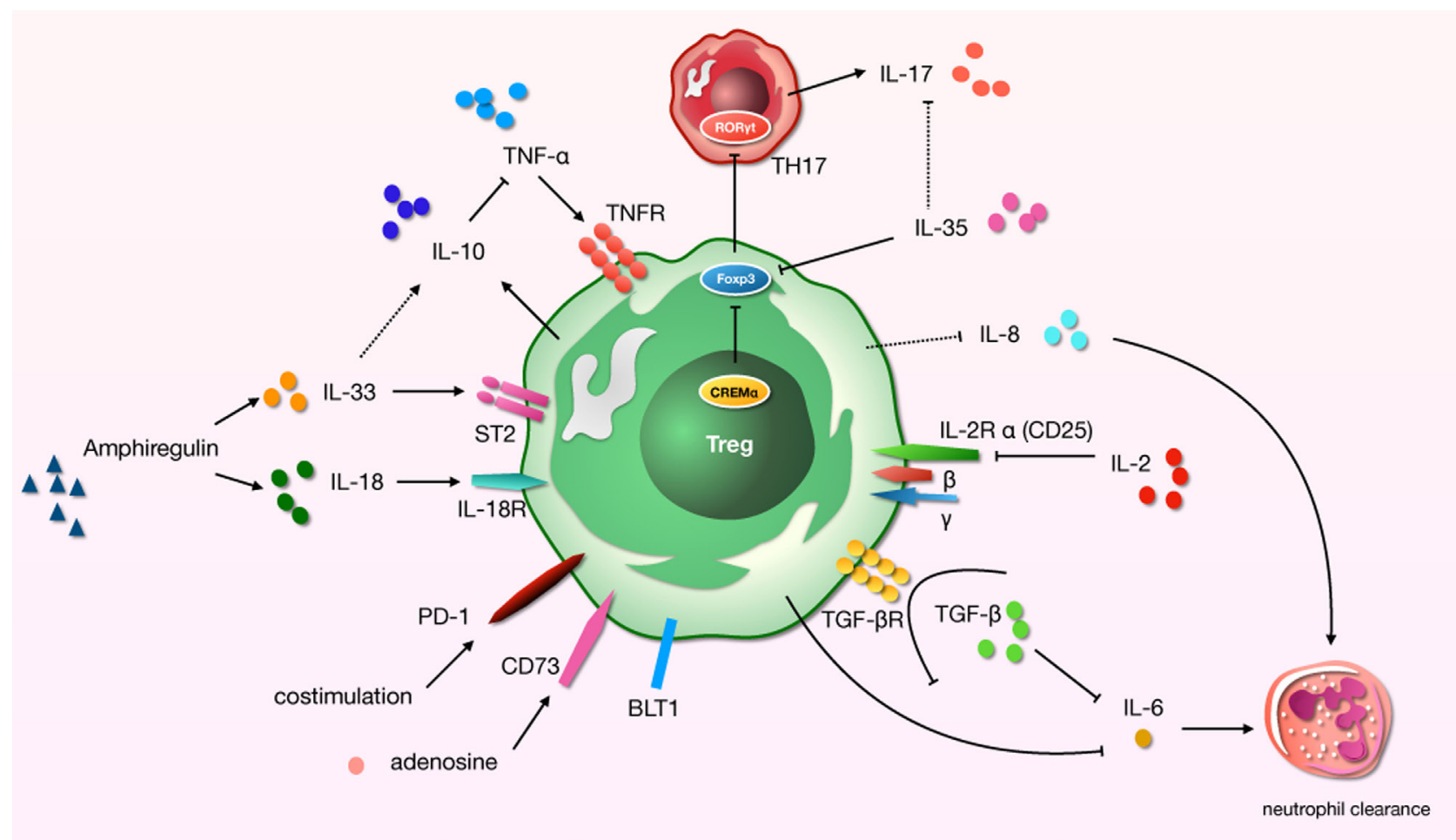

FIGURE 1 | A schematic about regulatory T cells (Tregs)-related cytokines and immunosuppressive molecules in acute lung injury (ALI) process. " $\rightarrow$ ": promote; "」": inhibit; "...": may play a role.

of TGF- $\beta$ (20). TGF- $\beta$ participates in many of the pathophysiologic processes of ARDS by stimulating the proliferation of fibroblasts, leading to the development of pulmonary fibrosis (67) and promoting the internalization of the $\alpha \beta \gamma$ epithelial sodium channel complex from the alveolar epithelial cell surface. This process leads to persistence of pulmonary edema $(68,69)$. As we know, lymphocytes can contribute to the resolution of inflammation through the clearance of alveolar neutrophils, which is the mechanism of pulmonary inflammation in ALI and ARDS. Research has confirmed that the neutrophil clearance rate can accelerated by Tregs $(4,20)$. IL- 6 seems to be a reliable biomarker of severity of illness in critical patients with high risk for ARDS, and it was found increased in the bronchoalveolar lavage fluid (BALF) and plasma in several ALI models $(70,71)$. Early studies showed that IL-6 strengthens the cytotoxic potential of polymorphonuclear leukocytes via selective enhancement of elastase release (72). TGF- $\beta$ functions as an inflammatory pathway of uncontrolled inflammation via p38MAPK, SMAD3 (73), or IL-6 to promote neutrophil clearance (74). Thus, Tregs inhibit the uncontrolled inflammation of ARDS through the secretion of TGF- $\beta$, which affects IL- 6 and then clears the neutrophils. But the debate continues regarding whether it acts as a counterregulatory mediator or pro-inflammatory principally. Follow-up studies have confirmed that IL-6 markedly diminishes lung injury in a hyperoxic model associated with the induction of Bcl-2 and TIMP-1 (75). According to the research of D'Alessio et al., Tregs orchestrated critical events to recovery via adoptive transfer after LPS-induced (intratracheal) ALI $(20,76)$. Interestingly, the absence of Tregs might contribute to the increased expression of the IL-6 gene persistently (76). Thus, the mechanism of Tregs reliance on IL-6 seems to differ in different types of ALI. On the other hand, low doses of IL-2 are the most successful strategy to "boost" Tregs in vivo so far (77). IL-2 is necessary for the development and maintenance of Foxp $3^{+} \mathrm{CD} 4^{+}$Tregs, which prevent the development of autoimmune disease $(78,79)$. The levels of IL-2 and Treg-related cytokines in BALF and serum gradually decreased in ALI over time (80). Animal studies have shown that in chorioamnionitis, systemic treatment with IL-2 expanded Tregs preferentially by increasing the ratio of Fox $3^{+} / \mathrm{CD}^{+}$in fetal lungs, thus improving lung function and modulating pulmonary inflammation (81). However, there is little evidence of ARDS/ALI induced by other causes.

\section{IL-8}

IL-8, a potent neutrophil attractant and activator, was found to be increased in the BALF of patients at risk who ultimately developed ARDS (82). A multiple logistic regression model incorporating oxygenation index, IL-8, and TNF-R2 was superior in predicting the composite outcome of mortality or severe morbidity (83). IL-8 plays a significant role in ALI via the formation of anti-IL-8 autoantibody, and IL-8 complexes and of those complexes' interactions with FcyRIIa receptors, 
leading to the development of ALI by effecting neutrophil apoptosis $(84,85)$. Limited research has found that Tregs exert an inhibitive effect on innate immune responses and neutrophil infiltration mediated by IL-8 (86). There is also evidence that decreased IL- 8 in the BALF and improvement of lung injuries are accompanied by increased $\mathrm{CD}^{+}{ }^{+}$Foxp $3^{+}$Tregs number and Foxp 3 transcription level of the lungs (87). But this evidence is of limited significance for the regulation of Tregs in ALI.

\section{IL-33 AND IL-18}

The role of IL-33 is not limited to Th2 response. By contrast, IL-33 is a potent (83) activator of group 2 innate lymphoid cells, Th1 cells, Tregs, and $\mathrm{CD}^{+} \mathrm{T}$ cells (88), and it is an immunostimulatory factor used to induce Treg expansion (89). It is released in the stage of tissue injury in sepsis and activates type 2 innate lymphoid cells that encourage the polarization of M2 macrophages. In this way, IL-10 enhances the amplification of Treg population (90). In ARDS, IL-33 level of serum were higher in patients with pulmonary factors; then pulmonary inflammation and injury were reduced by the treatment of IL-33 neutralizing antibody (19). In the lung, CD4 ${ }^{+} \mathrm{Foxp}^{+}$ Tregs expressed ST2, the IL-33 receptor. If exposed to IL-33, Tregs can upregulated the expression of GATA3 and ST2, then produced type 2 cytokines (91). In other studies, selective Tregs deficiency in amphiregulin cause the severe ALI and hypoxias during influenza virus infection; this mobilized Tregs in response to the IL-33 or IL-18 but not by $\mathrm{T}$ cell receptors signaling $(7,92)$. Early-stage serum IL-18 levels are among the signs reflecting the prognosis after 60 or more days in patients with ARDS (93). The pro-inflammatory role of IL-18 in ALI is related to the activation of NLRP3 through the activation of caspase-1 $(94,95)$ and the upregulation of IL-18-mediated neutrophil infiltration (96).

\section{Th17, IL-17, AND IL-35}

A balance between Th17 and Tregs may be essential for maintaining immune homeostasis and has long been thought to be an important factors in the development/prevention of autoimmune and inflammatory diseases (97). The severity of lung injury was associated with imbalanced T-cell subsets, which were related to the combined effect of increased pro-inflammatory (Th1) cells and decreased anti-inflammatory cells (Foxp ${ }^{3+}$ Tregs) (98). Th17/Treg imbalance favoring a Th17 shift indicates a potential therapeutic target to reduce lung injury and a novel risk indicator for early ARDS patients $(80,99)$. Meanwhile, IL-17-producing cells (Th17) have a pro-inflammatory effects. Studies have shown that elevated level of IL-17A in alveolar and circulating related to the increased percentages of alveolar neutrophils, greater alveolar permeability, and reduced organ dysfunction in ARDS (97, 100). We must pay attention to cyclic AMP-responsive

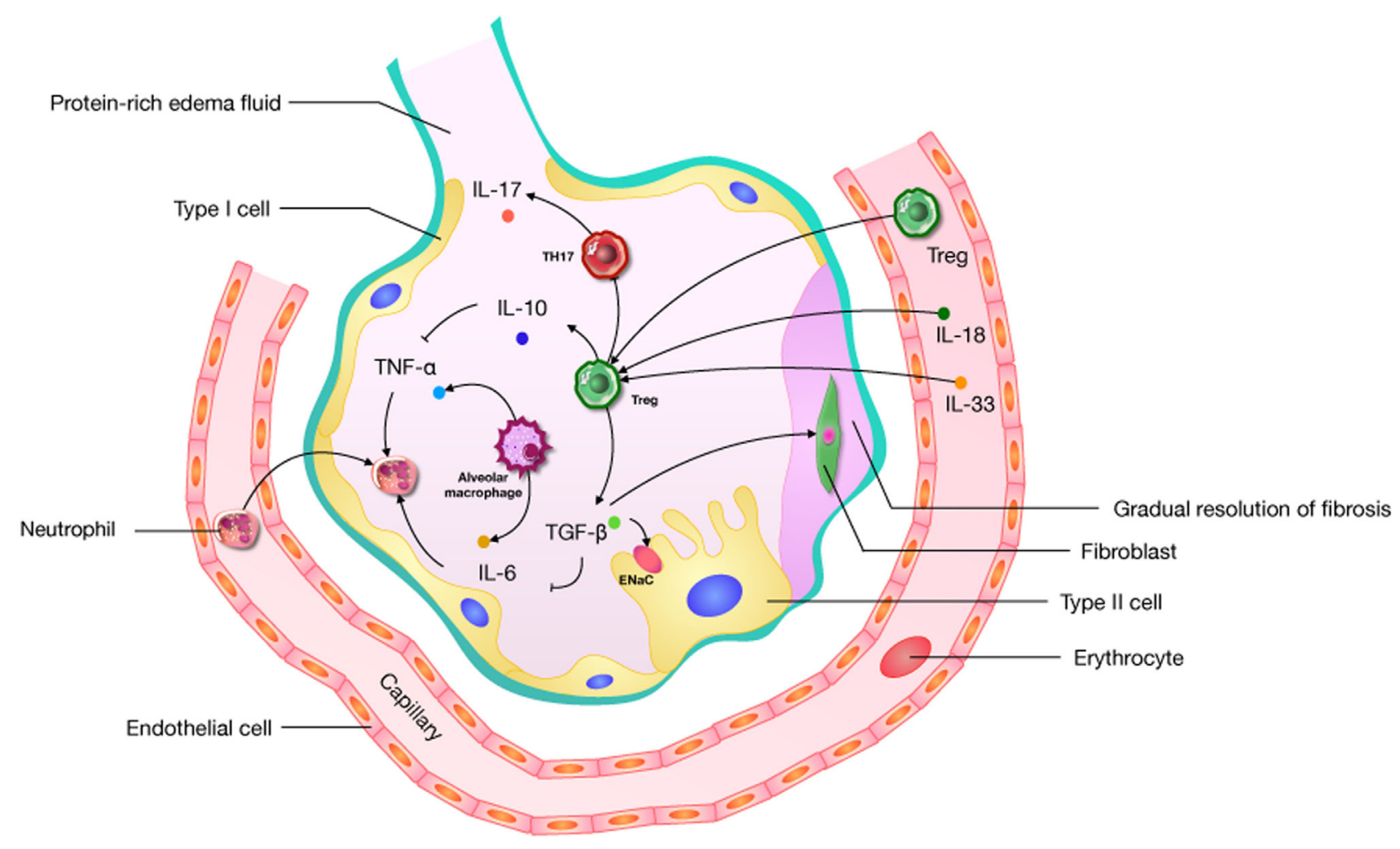

FIGURE 2 | A pathophysiological schematic about regulatory T cells (Tregs) improving the acute lung injury (ALI) process through the influence of cytokines (including TGF- $\beta$, IL-6, IL-10, IL-17, IL-18, and IL-33) which has been confirmed. ENaC: epithelial sodium channel; “ $\rightarrow$ ”: promote; " $\perp$ ": inhibit. 
element modulator- $\alpha$ (CREM $\alpha)$, overexpression of CREM $\alpha$ in $\mathrm{T}$ cells should change the inflammatory microenvironment. Levels of CREM $\alpha$ in T cells could determine the outcome of ALI, and upgraded CREM $\alpha$ contributes to increased IL-17 expression and decreased Foxp3, IL-2, and numbers of Tregs (101). Non-ALI research shows that IL-17-producing biTregs coincide with the progress of immuno-inflammation and tissue injury, and the specific elimination of ROR $\gamma \mathrm{t}$ activation in endogenous biTregs results in the improvement of pulmonary vasculitic injury (102). The evidence we were able to find about ALI is limited to pentoxifyllinum-induced increased cAMP in ARDS, which may restore the balance of Treg/Th17 via the transcriptional regulation of ROR $\gamma \mathrm{t}$ and Foxp3 partly through STAT3 signal (103).

IL-35 is a relatively newly identified cytokine obligatory for the regulatory and inhibit role of Tregs; it plays a vital function in prevention and cure in autoimmune diseases. One study shows that the degree of lung injury mitigation was accompanied by increased $\mathrm{CD}^{+}{ }^{+} \mathrm{Foxp}^{+}$Tregs number as well as the Foxp3 transcription level of lung and IL-35 level from the BALF in rats (87). But there is no direct research of the role and mechanism about Tregs and IL-35 in ALI. However, a study of pulmonary inflammatory disease (allergic airways disease) confirmed that IL-35 production by inducible costimulator-positive Tregs can suppress IL-17 production and thereby reverse the inflammation (104). Thus, the effect of IL-35 may be exerted by altering the expression of IL-17.

\section{OTHER IMMUNOSUPPRESSIVE MOLECULES}

Other immunosuppressive molecules also participate in the progress of ALI. In mice and patients with ALI, the alveolar recruitment of Tregs specifically mediated by the leukotriene B4-BLT1 pathway contributed to the resolution of lung inflammation $(20,105)$, particularly in the resolution of ALI fibroproliferation (21). And Tregs can modify the ALI-induced innate immune response directly, a process mediated in part by PD-1 (106). Furthermore, Ecto-5'-nucleotidase eNT (CD73) ${ }^{+}$Tregs have been found to contribute to adenosine-mediated resolution of ALI (107).

\section{CONCLUSION AND FUTURE PERSPECTIVES}

The diverse etiologies of ARDS limit the study of its mechanisms and therapies. Given the heterogeneity of ARDS, we may well be forced to focus on just one of its features, namely uncontrolled inflammation. Cytokines play a crucial role in creating an immunogenic microenvironment and therefore are key players in the promotion or inhibition ALI. Complex networks of cytokines and chemokines regulate the progression of ARDS. An activated immune system and immune cells (CD4, CD8, Th1, Th2, Th17, Tregs, and others) act as a significant role in this network. The role of Tregs is to prevent the development and extension of inflammatory diseases (36), and they can prevent the development of immune pathology and inflammation in the environmental/pulmonary interface involved in ALI. Based on the effect of uncontrolled inflammation in the promotion of ALI, it is possible that the disease's microenvironment may offer useful cues regarding Tregs, but this remains unclear. Some research suggests that Tregs can improve the ALI process through the influence of TGF- $\beta(68,69,73,74)$, IL-6 $(20,76)$, IL-10 (51, 58, 64), IL-17 (101), IL-18 (7, 92), and IL-33 (91) (Figure 2). What needs to be raised is that IL-17, generated by Th17 cells preferentially, has an abundant research about ARDS (108). The Th17/Treg balance toward Th17 cells might improve the aggregation of inflammatory mediators, and forming an amplificatory inflammatory loop to promote uncontrolled inflammation in patients with ARDS (99). In an IL-6-rich inflammatory microenvironment, Th17 enhanced while Tregs are suppressed (109). So the role of IL-6 in shifting Th17/Treg axis in ALI is worth noticing. And IL- 6 as a target for the treatment about Tregs should be considered.

There has also been some indirect evidence that Tregs have an impact on TNF- $\alpha(60,61)$, IL-2 $(81,101)$, and IL-8 (87). In addition, some immunosuppressive molecules [BLT1 $(20,101)$, PD-1 (106), and CD73 (107)] have also been shown to play an important role in Treg immune function in ALI. Hence, the manipulation of Tregs may represent a plausible target for treating ALI.

"Immune conditioning" may be a fashionable concept, but in essence it also points to the intervention of immune cells and their effects. Cell-based therapy for ARDS has the potential to be of therapeutic value (110-113). Various therapeutic approaches with some success in promoting Tregs have been investigated in diseases will provide some important clues to similar treatments for ARDS (114-117). Generally, Tregs have a protective effect and are beneficial to patients with ALI, but excessive suppression of inflammation is not an ideal outcome. Therefore, a dynamic assessment of the immune status in ALI is essential for the elucidation of its Treg-based therapy.

\section{AUTHOR CONTRIBUTIONS}

FX and SL wrote this manuscript. FX and HW revised this manuscript. FX, CW, and ZX searched and collected bibliography.

\section{FUNDING}

This study was supported by NSFC of China (81570069, to FX), Basic science and cutting-edge technology research projects of Chongqing Science and Technology Commission (cstc2016jcyjA0005, FX), Special fund of social undertakings and people's livelihood guarantee of Chongqing science and Technology Commission (cstc2017shmsA130072, FX), The Scientific \& Technological Research Program of Chongqing Municipal Education Commission (KJ1702034, FX), Medical research project of Chongqing City Health \& Family Planning committee (2017ZDXM007, FX), Chinese medicine science and technology project of Chongqing City Health \& Family Planning committee (ZY201702071, FX). 


\section{REFERENCES}

1. Combes A, Pesenti A, Ranieri VM. Fifty years of research in ARDS. Is extracorporeal circulation the future of acute respiratory distress syndrome management? Am J Respir Crit Care Med (2017) 195(9):1161-70. doi:10.1164/ rccm.201701-0217CP

2. Matthay MA, McAuley DF, Ware LB. Clinical trials in acute respiratory distress syndrome: challenges and opportunities. Lancet Respir Med (2017) 5(6):524-34. doi:10.1016/S2213-2600(17)30188-1

3. Ashbaugh DG, Bigelow DB, Petty TL, Levine BE. Acute respiratory distress in adults. Lancet (1967) 2(7511):319-23. doi:10.1016/S01406736(67)90168-7

4. Matthay MA, Ware LB, Zimmerman GA. The acute respiratory distress syndrome. J Clin Invest (2012) 122(8):2731-40. doi:10.1172/JCI60331

5. Ranieri VM, Rubenfeld GD, Thompson BT, Ferguson ND, Caldwell E, Fan E, et al. Acute respiratory distress syndrome: the Berlin definition. JAMA (2012) 307(23):2526-33. doi:10.1001/jama.2012.5669

6. Goronzy JJ, Weyand CM. Successful and maladaptive T cell aging. Immunity (2017) 46(3):364-78. doi:10.1016/j.immuni.2017.03.010

7. Arpaia N, Green JA, Moltedo B, Arvey A, Hemmers S, Yuan S, et al. A distinct function of regulatory T cells in tissue protection. Cell (2015) 162(5):1078-89. doi:10.1016/j.cell.2015.08.021

8. Lei H, Schmidt-Bleek K, Dienelt A, Reinke P, Volk HD. Regulatory T cellmediated anti-inflammatory effects promote successful tissue repair in both indirect and direct manners. Front Pharmacol (2015) 6:184. doi:10.3389/ fphar.2015.00184

9. Mold JE, Michaelsson J, Burt TD, Muench MO, Beckerman KP, Busch MP, et al. Maternal alloantigens promote the development of tolerogenic fetal regulatory T cells in utero. Science (2008) 322(5907):1562-5. doi:10.1126/ science.1164511

10. Sakaguchi S, Wing K, Onishi Y, Prieto-Martin P, Yamaguchi T. Regulatory T cells: how do they suppress immune responses? Int Immunol (2009) 21(10):1105-11. doi:10.1093/intimm/dxp095

11. Calfee CS, Delucchi K, Parsons PE, Thompson BT, Ware LB, Matthay MA. Subphenotypes in acute respiratory distress syndrome: latent class analysis of data from two randomised controlled trials. Lancet Respir Med (2014) 2(8):611-20. doi:10.1016/S2213-2600(14)70097-9

12. Mukhopadhyay S, Hoidal JR, Mukherjee TK. Role of TNFalpha in pulmonary pathophysiology. Respir Res (2006) 7:125. doi:10.1186/1465-9921-7-125

13. Wilson MR, Wakabayashi K, Bertok S, Oakley CM, Patel BV, O’Dea KP, et al. Inhibition of TNF receptor p55 by a domain antibody attenuates the initial phase of acid-induced lung injury in mice. Front Immunol (2017) 8:128. doi:10.3389/fimmu.2017.00128

14. Geiser T, Atabai K, Jarreau PH, Ware LB, Pugin J, Matthay MA. Pulmonary edema fluid from patients with acute lung injury augments in vitro alveolar epithelial repair by an IL-1beta-dependent mechanism. Am J Respir Crit Care Med (2001) 163(6):1384-8. doi:10.1164/ajrccm.163.6.2006131

15. Hierholzer C, Kalff JC, Omert L, Tsukada K, Loeffert JE, Watkins SC, et al. Interleukin- 6 production in hemorrhagic shock is accompanied by neutrophil recruitment and lung injury. Am J Physiol (1998) 275(3 Pt 1):L611-21.

16. Muir R, Osbourn M, Dubois AV, Doran E, Small DM, Monahan A, et al. Innate lymphoid cells are the predominant source of IL-17A during the early pathogenesis of acute respiratory distress syndrome. Am J Respir Crit Care Med (2016) 193(4):407-16. doi:10.1164/rccm.201410-1782OC

17. Jiang Z, Zhou Q, Gu C, Li D, Zhu L. Depletion of circulating monocytes suppresses IL-17 and HMGB1 expression in mice with LPS-induced acute lung injury. Am J Physiol Lung Cell Mol Physiol (2017) 312(2):L231-42. doi:10.1152/ajplung.00389.2016

18. Martinez-Gonzalez I, Roca O, Masclans JR, Moreno R, Salcedo MT, Baekelandt V, et al. Human mesenchymal stem cells overexpressing the IL-33 antagonist soluble IL-1 receptor-like-1 attenuate endotoxin-induced acute lung injury. Am J Respir Cell Mol Biol (2013) 49(4):552-62. doi:10.1165/ rcmb.2012-0406OC

19. Lin SH, Fu J, Wang CJ, Gao F, Feng XY, Liu Q, et al. Inflammation elevated IL-33 originating from the lung mediates inflammation in acute lung injury. Clin Immunol (2016) 173:32-43. doi:10.1016/j.clim.2016.10.014

20. D'Alessio FR, Tsushima K, Aggarwal NR, West EE, Willett MH, Britos MF, et al. CD4+CD25+Foxp3+ Tregs resolve experimental lung injury in mice and are present in humans with acute lung injury. J Clin Invest (2009) 119(10):2898-913. doi:10.1172/JCI36498

21. Garibaldi BT, D'Alessio FR, Mock JR, Files DC, Chau E, Eto Y, et al. Regulatory $\mathrm{T}$ cells reduce acute lung injury fibroproliferation by decreasing fibrocyte recruitment. Am J Respir Cell Mol Biol (2013) 48(1):35-43. doi:10.1165/rcmb. 2012-0198OC

22. Singer BD, Mock JR, Aggarwal NR, Garibaldi BT, Sidhaye VK, Florez MA, et al. Regulatory T cell DNA methyltransferase inhibition accelerates resolution of lung inflammation. Am J Respir Cell Mol Biol (2015) 52(5):641-52. doi:10.1165/rcmb.2014-0327OC

23. Theoharides TC, Conti P. Mast cells. The Jekyll and Hyde of tumor growth. Trends Immunol (2004) 25(5):235-41. doi:10.1016/j.it.2004.02.013

24. Galli SJ, Kalesnikoff J, Grimbaldeston MA, Piliponsky AM, Williams CM, Tsai M. Mast cells as "tunable" effector and immunoregulatory cells: recent advances. Annu Rev Immunol (2005) 23:749-86. doi:10.1146/annurev. immunol.21.120601.141025

25. Zygmunt B, Veldhoen M. T helper cell differentiation: more than just cytokines. Adv Immunol (2011) 109:159-96. doi:10.1016/B978-0-12-3876645.00005-4

26. Brucklacher-Waldert V, Ferreira C, Stebegg M, Fesneau O, Innocentin S, Marie JC, et al. Cellular stress in the context of an inflammatory environment supports TGF-beta-independent T helper-17 differentiation. Cell Rep (2017) 19(11):2357-70. doi:10.1016/j.celrep.2017.05.052

27. Duhen T, Duhen R, Lanzavecchia A, Sallusto F, Campbell DJ. Functionally distinct subsets of human FOXP3+ Treg cells that phenotypically mirror effector Th cells. Blood (2012) 119(19):4430-40. doi:10.1182/blood-2011-11-392324

28. Pawankar R, Hayashi M, Yamanishi S, Igarashi T. The paradigm of cytokine networks in allergic airway inflammation. Curr Opin Allergy Clin Immunol (2015) 15(1):41-8. doi:10.1097/ACI.0000000000000129

29. Gershon RK. A disquisition on suppressor T cells. Transplant Rev (1975) 26:170-85

30. De Rosa V, Di Rella F, Di Giacomo A, Matarese G. Regulatory T cells as suppressors of anti-tumor immunity: role of metabolism. Cytokine Growth Factor Rev (2017) 35:15-25. doi:10.1016/j.cytogfr.2017.04.001

31. Rosenblum MD, Way SS, Abbas AK. Regulatory T cell memory. Nat Rev Immunol (2016) 16(2):90-101. doi:10.1038/nri.2015.1

32. Abbas AK, Benoist C, Bluestone JA, Campbell DJ, Ghosh S, Hori S, et al. Regulatory T cells: recommendations to simplify the nomenclature. Nat Immunol (2013) 14(4):307-8. doi:10.1038/ni.2554

33. Baecher-Allan C, Brown JA, Freeman GJ, Hafler DA. CD4+CD25 high regulatory cells in human peripheral blood. J Immunol (2001) 167(3):1245-53. doi:10.4049/jimmunol.167.3.1245

34. Ng WF, Duggan PJ, Ponchel F, Matarese G, Lombardi G, Edwards AD, et al. Human CD4(+)CD25(+) cells: a naturally occurring population of regulatory T cells. Blood (2001) 98(9):2736-44. doi:10.1182/blood.V98.9.2736

35. Roncador G, Brown PJ, Maestre L, Hue S, Martinez-Torrecuadrada JL, Ling KL, et al. Analysis of FOXP3 protein expression in human CD4+CD25+ regulatory T cells at the single-cell level. Eur J Immunol (2005) 35(6):1681-91. doi:10.1002/eji.200526189

36. Noack M, Miossec $\mathrm{P}$. Th17 and regulatory T cell balance in autoimmune and inflammatory diseases. Autoimmun Rev (2014) 13(6):668-77. doi:10.1016/j. autrev.2013.12.004

37. Huynh A, DuPage M, Priyadharshini B, Sage PT, Quiros J, Borges CM, et al. Control of PI(3) kinase in Treg cells maintains homeostasis and lineage stability. Nat Immunol (2015) 16(2):188-96. doi:10.1038/ni.3077

38. Shrestha S, Yang K, Guy C, Vogel P, Neale G, Chi H. Treg cells require the phosphatase PTEN to restrain TH1 and TFH cell responses. Nat Immunol (2015) 16(2):178-87. doi:10.1038/ni.3076

39. Mrass P, Oruganti SR, Fricke GM, Tafoya J, Byrum JR, Yang L, et al. ROCK regulates the intermittent mode of interstitial $\mathrm{T}$ cell migration in inflamed lungs. Nat Commun (2017) 8(1):1010. doi:10.1038/s41467-017-01032-2

40. Bennett CL, Christie J, Ramsdell F, Brunkow ME, Ferguson PJ, Whitesell L, et al. The immune dysregulation, polyendocrinopathy, enteropathy, X-linked syndrome (IPEX) is caused by mutations of FOXP3. Nat Genet (2001) 27(1):20-1. doi:10.1038/83713

41. Fontenot JD, Gavin MA, Rudensky AY. Foxp3 programs the development and function of CD4+CD25+ regulatory T cells. Nat Immunol (2003) 4(4): 330-6. doi:10.1038/ni904 
42. Sakaguchi S, Wing K, Yamaguchi T. Dynamics of peripheral tolerance and immune regulation mediated by Treg. Eur J Immunol (2009) 39(9):2331-6. doi:10.1002/eji.200939688

43. Tiemessen MM, Jagger AL, Evans HG, van Herwijnen MJ, John S, Taams LS. CD4+CD25+Foxp3+ regulatory T cells induce alternative activation of human monocytes/macrophages. Proc Natl Acad Sci U S A (2007) 104(49):19446-51. doi:10.1073/pnas.0706832104

44. Wing K, Sakaguchi S. Regulatory T cells exert checks and balances on self tolerance and autoimmunity. Nat Immunol (2010) 11(1):7-13. doi:10.1038/ ni. 1818

45. Downs-Canner S, Berkey S, Delgoffe GM, Edwards RP, Curiel T, Odunsi K, et al. Suppressive IL-17A(+)Foxp3(+) and ex-Th17 IL-17A(neg)Foxp3(+) T(reg) cells are a source of tumour-associated T(reg) cells. Nat Commun (2017) 8:14649. doi:10.1038/ncomms14649

46. Komatsu N, Okamoto K, Sawa S, Nakashima T, Oh-hora M, Kodama T, et al. Pathogenic conversion of Foxp3 $+\mathrm{T}$ cells into TH17 cells in autoimmune arthritis. Nat Med (2014) 20(1):62-8. doi:10.1038/nm.3432

47. Saito S, Rosol TJ, Saito M, Ngan PW, Shanfeld J, Davidovitch Z. Boneresorbing activity and prostaglandin $\mathrm{E}$ produced by human periodontal ligament cells in vitro. J Bone Miner Res (1990) 5(10):1013-8. doi:10.1002/ jbmr.5650051004

48. Twentyman PR, Wright KA, Rhodes T. Radiation response of human lung cancer cells with inherent and acquired resistance to cisplatin. Int J Radiat Oncol Biol Phys (1991) 20(2):217-20. doi:10.1016/0360-3016(91)90093-J

49. Gagliani N, Amezcua Vesely MC, Iseppon A, Brockmann L, Xu H, Palm NW. Th17 cells transdifferentiate into regulatory $\mathrm{T}$ cells during resolution of inflammation. Nature (2015) 523(7559):221-5. doi:10.1038/nature14452

50. Obermajer N, Popp FC, Soeder Y, Haarer J, Geissler EK, Schlitt HJ. Conversion of Th17 into IL-17A(neg) regulatory T cells: a novel mechanism in prolonged allograft survival promoted by mesenchymal stem cell-supported minimized immunosuppressive therapy. J Immunol (2014) 193(10):4988-99. doi:10.4049/jimmunol.1401776

51. Rubtsov YP, Rasmussen JP, Chi EY, Fontenot J, Castelli L, Ye X, et al. Regulatory T cell-derived interleukin-10 limits inflammation at environmental interfaces. Immunity (2008) 28(4):546-58. doi:10.1016/j.immuni.2008. 02.017

52. Kalathil SG, Lugade AA, Pradhan V, Miller A, Parameswaran GI, Sethi S, et al. T-regulatory cells and programmed death $1+\mathrm{T}$ cells contribute to effector T-cell dysfunction in patients with chronic obstructive pulmonary disease. Am J Respir Crit Care Med (2014) 190(1):40-50. doi:10.1164/rccm. 201312-2293OC

53. Li XN, Pan X, Qiu D. Imbalances of Th17 and Treg cells and their respective cytokines in COPD patients by disease stage. Int J Clin Exp Med (2014) 7(12):5324-9.

54. Maynard CL, Harrington LE, Janowski KM, Oliver JR, Zindl CL, Rudensky AY, et al. Regulatory T cells expressing interleukin 10 develop from Foxp3+ and Foxp3- precursor cells in the absence of interleukin 10. Nat Immunol (2007) 8(9):931-41. doi:10.1038/ni1504

55. Almanan M, Raynor J, Sholl A, Wang M, Chougnet C, Cardin RD, et al. Tissue-specific control of latent CMV reactivation by regulatory T cells. PLoS Pathog (2017) 13(8):e1006507. doi:10.1371/journal.ppat.1006507

56. Meduri GU, Kohler G, Headley S, Tolley E, Stentz F, Postlethwaite A. Inflammatory cytokines in the BAL of patients with ARDS. Persistent elevation over time predicts poor outcome. Chest (1995) 108(5):1303-14. doi:10.1378/chest.108.5.1303

57. Mock JR, Garibaldi BT, Aggarwal NR, Jenkins J, Limjunyawong N, Singer BD, et al. Foxp3+ regulatory $\mathrm{T}$ cells promote lung epithelial proliferation. Mucosal Immunol (2014) 7(6):1440-51. doi:10.1038/mi. 2014.33

58. Venet F, Chung CS, Huang X, Lomas-Neira J, Chen Y, Ayala A. Lymphocytes in the development of lung inflammation: a role for regulatory CD4+ T cells in indirect pulmonary lung injury. J Immunol (2009) 183(5):3472-80. doi:10.4049/jimmunol.0804119

59. Rosenthal C, Caronia C, Quinn C, Lugo N, Sagy M. A comparison among animal models of acute lung injury. Crit Care Med (1998) 26(5):912-6. doi:10.1097/00003246-199805000-00027

60. Nie H, Zheng Y, Li R, Guo TB, He D, Fang L, et al. Phosphorylation of FOXP3 controls regulatory $\mathrm{T}$ cell function and is inhibited by TNF-alpha in rheumatoid arthritis. Nat Med (2013) 19(3):322-8. doi:10.1038/nm.3085
61. Sun J, Han ZB, Liao W, Yang SG, Yang Z, Yu J, et al. Intrapulmonary delivery of human umbilical cord mesenchymal stem cells attenuates acute lung injury by expanding CD4+CD25+ Forkhead Boxp3 (FOXP3)+ regulatory T cells and balancing anti- and pro-inflammatory factors. Cell Physiol Biochem (2011) 27(5):587-96. doi:10.1159/000329980

62. Zhu J, Yamane H, Paul WE. Differentiation of effector CD4 T cell populations $\left(^{*}\right)$. Annu Rev Immunol (2010) 28:445-89. doi:10.1146/ annurev-immunol-030409-101212

63. Inoue G. Effect of interleukin-10 (IL-10) on experimental LPS-induced acute lung injury. J Infect Chemother (2000) 6(1):51-60. doi:10.1007/ s101560000021

64. Kapur R, Kim M, Aslam R, McVey MJ, Tabuchi A, Luo A, et al. T regulatory cells and dendritic cells protect against transfusion-related acute lung injury via IL-10. Blood (2017) 129(18):2557-69. doi:10.1182/blood-2016-12758185

65. Sakaguchi S, Yamaguchi T, Nomura T, Ono M. Regulatory T cells and immune tolerance. Cell (2008) 133(5):775-87. doi:10.1016/j.cell.2008.05.009

66. Kimura A, Kishimoto T. IL-6: regulator of Treg/Th17 balance. Eur J Immunol (2010) 40(7):1830-5. doi:10.1002/eji.201040391

67. Deng X, Jin K, Li Y, Gu W, Liu M, Zhou L. Platelet-derived growth factor and transforming growth factor betal regulate ARDS-associated lung fibrosis through distinct signaling pathways. Cell Physiol Biochem (2015) 36(3):937-46. doi:10.1159/000430268

68. Frank JA, Matthay MA. TGF-beta and lung fluid balance in ARDS. Proc Natl Acad Sci U S A (2014) 111(3):885-6. doi:10.1073/pnas.1322478111

69. Peters DM, Vadasz I, Wujak L, Wygrecka M, Olschewski A, Becker C, et al. TGF-beta directs trafficking of the epithelial sodium channel ENaC which has implications for ion and fluid transport in acute lung injury. Proc Natl Acad Sci U S A (2014) 111(3):E374-83. doi:10.1073/pnas. 1306798111

70. Denis M, Guojian L, Widmer M, Cantin A. A mouse model of lung injury induced by microbial products: implication of tumor necrosis factor. Am J Respir Cell Mol Biol (1994) 10(6):658-64. doi:10.1165/ajrcmb.10.6. 8003342

71. Chen W, Sammani S, Mitra S, Ma SF, Garcia JG, Jacobson JR. Critical role for integrin-beta 4 in the attenuation of murine acute lung injury by simvastatin. Am J Physiol Lung Cell Mol Physiol (2012) 303(4):L279-85. doi:10.1152/ ajplung.00361.2011

72. Johnson JL, Moore EE, Tamura DY, Zallen G, Biffl WL, Silliman CC. Interleukin- 6 augments neutrophil cytotoxic potential via selective enhancement of elastase release. J Surg Res (1998) 76(1):91-4. doi:10.1006/jsre. 1998.5295

73. Xu F, Lin SH, Yang YZ, Guo R, Cao J, Liu Q. The effect of curcumin on sepsis-induced acute lung injury in a rat model through the inhibition of the TGF-betal/SMAD3 pathway. Int Immunopharmacol (2013) 16(1):1-6. doi:10.1016/j.intimp.2013.03.014

74. Ganeshan K, Johnston LK, Bryce PJ. TGF-betal limits the onset of innate lung inflammation by promoting mast cell-derived IL-6. J Immunol (2013) 190(11):5731-8. doi:10.4049/jimmunol.1203362

75. Ward NS, Waxman AB, Homer RJ, Mantell LL, Einarsson O, Du Y, et al. Interleukin-6-induced protection in hyperoxic acute lung injury. Am J Respir Cell Mol Biol (2000) 22(5):535-42. doi:10.1165/ajrcmb.22.5.3808

76. Aggarwal NR, D'Alessio FR, Tsushima K, Sidhaye VK, Cheadle C, Grigoryev DN, et al. Regulatory $\mathrm{T}$ cell-mediated resolution of lung injury: identification of potential target genes via expression profiling. Physiol Genomics (2010) 41(2):109-19. doi:10.1152/physiolgenomics.00131.2009

77. Dawson NAJ, Vent-Schmidt J, Levings MK. Engineered tolerance: tailoring development, function, and antigen-specificity of regulatory T cells. Front Immunol (2017) 8:1460. doi:10.3389/fimmu.2017.01460

78. Yuan X, Cheng G, Malek TR. The importance of regulatory T-cell heterogeneity in maintaining self-tolerance. Immunol Rev (2014) 259(1):103-14. doi:10.1111/imr.12163

79. Botta D, Fuller MJ, Marquez-Lago TT, Bachus H, Bradley JE, Weinmann AS, et al. Dynamic regulation of $\mathrm{T}$ follicular regulatory cell responses by interleukin 2 during influenza infection. Nat Immunol (2017) 18(11):1249-60. doi:10.1038/ni.3837

80. Zhang F, Li MY, Lan YT, Wang CB. Imbalance of Th17/Tregs in rats with smoke inhalation-induced acute lung injury. Sci Rep (2016) 6:21348. doi: $10.1038 /$ srep 21348 
81. Willems MG, Ophelders DR, Nikiforou M, Jellema RK, Butz A, Delhaas T, et al. Systemic interleukin-2 administration improves lung function and modulates chorioamnionitis-induced pulmonary inflammation in the ovine fetus. Am J Physiol Lung Cell Mol Physiol (2016) 310(1):L1-7. doi:10.1152/ ajplung.00289.2015

82. Donnelly SC, Strieter RM, Kunkel SL, Walz A, Robertson CR, Carter DC, et al. Interleukin-8 and development of adult respiratory distress syndrome in at-risk patient groups. Lancet (1993) 341(8846):643-7. doi:10.1016/ 0140-6736(93)90416-E

83. Zinter MS, Orwoll BE, Spicer AC, Alkhouli MF, Calfee CS, Matthay MA, et al. Incorporating inflammation into mortality risk in pediatric acute respiratory distress syndrome. Crit Care Med (2017) 45(5):858-66. doi:10.1097/ CCM.0000000000002370

84. Krupa A, Kato H, Matthay MA, Kurdowska AK. Proinflammatory activity of anti-IL-8 autoantibody:IL-8 complexes in alveolar edema fluid from patients with acute lung injury. Am J Physiol Lung Cell Mol Physiol (2004) 286(6):L1105-13. doi:10.1152/ajplung.00277.2003

85. Fudala R, Krupa A, Stankowska D, Allen TC, Kurdowska AK. Antiinterleukin-8 autoantibody:interleukin-8 immune complexes in acute lung injury/acute respiratory distress syndrome. Clin Sci (Lond) (2008) 114(6):403-12. doi:10.1042/CS20070272

86. Tiriveedhi V, Takenaka M, Ramachandran S, Gelman AE, Subramanian V, Patterson GA, et al. T regulatory cells play a significant role in modulating MHC class I antibody-induced obliterative airway disease. Am J Transplant (2012) 12(10):2663-74. doi:10.1111/j.1600-6143.2012.04191.x

87. Bai J, Qiu SL, Zhong XN, Huang QP, He ZY, Zhang JQ, et al. Erythromycin enhances CD4+Foxp3+ regulatory T-cell responses in a rat model of smoke-induced lung inflammation. Mediators Inflamm (2012) 2012:410232. doi:10.1155/2012/410232

88. Hodzic Z, Schill EM, Bolock AM, Good M. IL-33 and the intestine: the good, the bad, and the inflammatory. Cytokine (2017) 100:1-10. doi:10.1016/j. cyto.2017.06.017

89. Ryba-Stanislawowska M, Werner P, Skrzypkowska M, Brandt A, Mysliwska J. IL-33 effect on quantitative changes of CD4(+)CD25(high) FOXP3(+) regulatory $\mathrm{T}$ cells in children with type 1 diabetes. Mediators Inflamm (2016) 2016:9429760. doi:10.1155/2016/9429760

90. Nascimento DC, Melo PH, Pineros AR, Ferreira RG, Colon DF, Donate PB, et al. IL-33 contributes to sepsis-induced long-term immunosuppression by expanding the regulatory T cell population. Nat Commun (2017) 8:14919. doi:10.1038/ncomms14919

91. Chen CC, Kobayashi T, Iijima K, Hsu FC, Kita H. IL-33 dysregulates regulatory $\mathrm{T}$ cells and impairs established immunologic tolerance in the lungs. J Allergy Clin Immunol (2017) 140(5):1351-63.e7. doi:10.1016/j.jaci.2017. 01.015

92. Vasanthakumar A, Kallies A. The regulatory T cell: jack-of-all-trades. Trends Immunol (2015) 36(12):756-8. doi:10.1016/j.it.2015.10.002

93. Makabe H, Kojika M, Takahashi G, Matsumoto N, Shibata S, Suzuki Y, et al. Interleukin-18 levels reflect the long-term prognosis of acute lung injury and acute respiratory distress syndrome. J Anesth (2012) 26(5):658-63. doi:10.1007/s00540-012-1409-3

94. Tsutsui H, Nakanishi K. Immunotherapeutic applications of IL-18. Immunotherapy (2012) 4(12):1883-94. doi:10.2217/imt.12.137

95. Fusco R, Gugliandolo E, Biundo F, Campolo M, Di Paola R, Cuzzocrea S. Inhibition of inflammasome activation improves lung acute injury induced by carrageenan in a mouse model of pleurisy. FASEB J (2017) 31(8):3497-511. doi:10.1096/fj.201601349R

96. Li X, Kovacs EJ, Schwacha MG, Chaudry IH, Choudhry MA. Acute alcohol intoxication increases interleukin-18-mediated neutrophil infiltration and lung inflammation following burn injury in rats. Am J Physiol Lung Cell Mol Physiol (2007) 292(5):L1193-201. doi:10.1152/ajplung.00408. 2006

97. Dai H, Xu L, Tang Y, Liu Z, Sun T. Treatment with a neutralising anti-rat interleukin-17 antibody after multiple-trauma reduces lung inflammation. Injury (2015) 46(8):1465-70. doi:10.1016/j.injury.2015.05.016

98. Li G, Cao Y, Sun Y, Xu R, Zheng Z, Song H. Ultrafine particles in the airway aggravated experimental lung injury through impairment in Treg function. Biochem Biophys Res Commun (2016) 478(1):494-500. doi:10.1016/j.bbrc. 2016.05.059
99. Yu ZX, Ji MS, Yan J, Cai Y, Liu J, Yang HF, et al. The ratio of Th17/Treg cells as a risk indicator in early acute respiratory distress syndrome. Crit Care (2015) 19:82. doi:10.1186/s13054-015-0811-2

100. Mikacenic C, Hansen EE, Radella F, Gharib SA, Stapleton RD, Wurfel MM. Interleukin-17A Is associated with alveolar inflammation and poor outcomes in acute respiratory distress syndrome. Crit Care Med (2016) 44(3):496-502. doi:10.1097/CCM.0000000000001409

101. Verjans E, Ohl K, Yu Y, Lippe R, Schippers A, Wiener A, et al. Overexpression of CREMalpha in T cells aggravates lipopolysaccharide-induced acute lung injury. J Immunol (2013) 191(3):1316-23. doi:10.4049/jimmunol. 1203147

102. Kluger MA, Nosko A, Ramcke T, Goerke B, Meyer MC, Wegscheid C, et al. RORgammat expression in Tregs promotes systemic lupus erythematosus via IL-17 secretion, alteration of Treg phenotype and suppression of Th2 responses. Clin Exp Immunol (2017) 188(1):63-78. doi:10.1111/cei.12905

103. Li Q, Hu X, Sun R, Tu Y, Gong F, Ni Y. Resolution acute respiratory distress syndrome through reversing the imbalance of Treg/Th17 by targeting the cAMP signaling pathway. Mol Med Rep (2016) 14(1):343-8. doi:10.3892/ mmr.2016.5222

104. Whitehead GS, Wilson RH, Nakano K, Burch LH, Nakano H, Cook DN. IL35 production by inducible costimulator (ICOS)-positive regulatory $\mathrm{T}$ cells reverses established IL-17-dependent allergic airways disease. J Allergy Clin Immunol (2012) 129(1):e201-5. doi:10.1016/j.jaci.2011.08.009

105. Wang L, Zhao L, Lv J, Yin Q, Liang X, Chu Y, et al. BLT1-dependent alveolar recruitment of $\mathrm{CD} 4(+) \mathrm{CD} 25(+)$ Foxp3(+) regulatory $\mathrm{T}$ cells is important for resolution of acute lung injury. Am J Respir Crit Care Med (2012) 186(10):989-98. doi:10.1164/rccm.201202-0261OC

106. Tang L, Bai J, Chung CS, Lomas-Neira J, Chen Y, Huang X, et al. Active players in resolution of shock/sepsis induced indirect lung injury: immunomodulatory effects of Tregs and PD-1. J Leukoc Biol (2014) 96(5):809-20. doi:10.1189/jlb.4MA1213-647RR

107. Ehrentraut H, Clambey ET, McNamee EN, Brodsky KS, Ehrentraut SF, Poth JM, et al. CD73+ regulatory T cells contribute to adenosine-mediated resolution of acute lung injury. FASEB J (2013) 27(6):2207-19. doi:10.1096/ f. $12-225201$

108. Li C, Yang P, Sun Y, Li T, Wang C, Wang Z. IL-17 response mediates acute lung injury induced by the 2009 pandemic influenza A (H1N1) virus. Cell Res (2012) 22(3):528-38. doi:10.1038/cr.2011.165

109. Barbi J, Pardoll D, Pan F. Metabolic control of the Treg/Th17 axis. Immunol Rev (2013) 252(1):52-77. doi:10.1111/imr.12029

110. Tonelli AR, Zein J, Adams J, Ioannidis JP. Effects of interventions on survival in acute respiratory distress syndrome: an umbrella review of 159 published randomized trials and 29 meta-analyses. Intensive Care Med (2014) 40(6):769-87. doi:10.1007/s00134-014-3272-1

111. Laffey JG, Matthay MA. Fifty years of research in ARDS. Cell-based therapy for acute respiratory distress syndrome. Biology and potential therapeutic value. Am JRespir Crit Care Med (2017) 196(3):266-73. doi:10.1164/ rccm.201701-0107CP

112. Huang SX, Islam MN, O’Neill J, Hu Z, Yang YG, Chen YW, et al. Efficient generation of lung and airway epithelial cells from human pluripotent stem cells. Nat Biotechnol (2014) 32(1):84-91. doi:10.1038/nbt.2754

113. McIntyre BA, Alev C, Mechael R, Salci KR, Lee JB, Fiebig-Comyn A, et al. Expansive generation of functional airway epithelium from human embryonic stem cells. Stem Cells Transl Med (2014) 3(1):7-17. doi:10.5966/ sctm.2013-0119

114. Yin X, Liang Z, Yun Y, Pei L. Intravenous transplantation of BMP2 transduced endothelial progenitor cells attenuates lipopolysaccharide-induced acute lung injury in rats. Cell Physiol Biochem (2015) 35(6):2149-58. doi:10.1159/000374020

115. Trzonkowski P, Bieniaszewska M, Juscinska J, Dobyszuk A, Krzystyniak A, Marek N, et al. First-in-man clinical results of the treatment of patients with graft versus host disease with human ex vivo expanded CD4+CD25+CD127T regulatory cells. Clin Immunol (2009) 133(1):22-6. doi:10.1016/j.clim. 2009.06.001

116. Brunstein CG, Miller JS, Cao Q, McKenna DH, Hippen KL, Curtsinger J, et al. Infusion of ex vivo expanded T regulatory cells in adults transplanted with umbilical cord blood: safety profile and detection kinetics. Blood (2011) 117(3):1061-70. doi:10.1182/blood-2010-07-293795 
117. Bluestone JA, Buckner JH, Fitch M, Gitelman SE, Gupta S, Hellerstein MK, et al. Type 1 diabetes immunotherapy using polyclonal regulatory $\mathrm{T}$ cells. Sci Transl Med (2015) 7(315):315ra189. doi:10.1126/scitranslmed.aad4134

Conflict of Interest Statement: The authors declare that the research was conducted in the absence of any commercial or financial relationships that could be construed as a potential conflict of interest.
Copyright $\odot 2018 \mathrm{Lin}, \mathrm{Wu}$, Wang, Xiao and Xu. This is an open-access article distributed under the terms of the Creative Commons Attribution License (CC BY).

The use, distribution or reproduction in other forums is permitted, provided the original author(s) and the copyright owner(s) are credited and that the original publication in this journal is cited, in accordance with accepted academic practice. No use, distribution or reproduction is permitted which does not comply with these terms. 